\title{
Analysis, Design, and Construction of a Base-Isolated Multiple Building Structure
}

\author{
Stefano Sorace ${ }^{1}$ and Gloria Terenzi ${ }^{2}$ \\ ${ }^{1}$ Department of Civil Engineering and Architecture, University of Udine, Via delle Scienze 206, 33100 Udine, Italy \\ ${ }^{2}$ Department of Civil and Environmental Engineering, University of Florence, Via S. Marta 3, 50139 Florence, Italy
}

Correspondence should be addressed to Stefano Sorace; stefano.sorace@uniud.it

Received 13 March 2014; Accepted 2 July 2014; Published 7 August 2014

Academic Editor: Polat Gülkan

Copyright $\odot 2014$ S. Sorace and G. Terenzi. This is an open access article distributed under the Creative Commons Attribution License, which permits unrestricted use, distribution, and reproduction in any medium, provided the original work is properly cited.

\begin{abstract}
The analysis and design of a multiple residential building, seismically protected by a base isolation system incorporating double friction pendulum sliders as protective devices, are presented in the paper. The building, situated in the suburban area of Florence, is composed of four independent reinforced concrete framed structures, mutually separated by three thermal expansion joints. The plan is L-shaped, with dimensions of about $75 \mathrm{~m}$ in the longitudinal direction and about $30 \mathrm{~m}$ along the longest side of the transversal direction. These characteristics identify the structure as the largest example of a base-isolated "artificial ground" ever built in Italy. The base isolation solution guarantees lower costs, a much greater performance, and a finer architectural look, as compared to a conventional fixed-base antiseismic design. The characteristics of the building and the isolators, the mechanical properties and the experimental characterization campaign and preliminary sizing carried out on the latter, and the nonlinear time-history design and performance assessment analyses developed on the base isolated building are reported in this paper, along with details about the installation of the isolators and the plants and highlights of the construction works.
\end{abstract}

\section{Introduction}

Base isolation is nowadays a well-established and viable antiseismic design strategy for new buildings and bridges, as well as for the retrofit of existing ones, with several thousand applications in over 30 earthquake-prone countries worldwide. The use of this technology, originally restricted to massive and stiff structures, has been progressively extended in the past decade to include slender and high-rise buildings, as well as groups of structures built on a single platform (also labelled as "artificial ground") [1]. This is a consequence of the increase in the fundamental vibration period targeted in base-isolated conditions, following the incorporation of the latest generation of isolators, characterized by very low translational stiffness. The period, normally fixed at $2-2.5 \mathrm{~s}$ in early designs, was subsequently raised to $3-3.5 \mathrm{~s}$, for standard buildings, and to over $4 \mathrm{~s}$, for special structures. This allowed extending the benefits of seismic isolation to wider classes of applications, that is, the new structural configurations above and other notably demanding conditions, and, namely, significant geometrical irregularities in plan and/or elevation
[2]; possible effects of near-fault earthquake components in the construction site [3-6]; a trend towards marked reductions in width of the separation gaps between adjacent structures built on one mobile platform [7] and towards simplified details of any installations crossing the isolation plan [3]; null or very limited structural and nonstructural damage to buildings [4] and total recentering capacity of the isolation systems, also for the highest levels of normative design earthquakes [8,9]; and progressive cuts in costs, which aimed at improving the competitiveness of base isolation with respect to other seismic protection strategies [10].

The wider application fields of seismic isolation and the growing complexity of the architectural and structural layouts involve developing more careful verification and performance assessment analyses, as compared to the conventional design approaches based on simplified linear models, both of the isolation system and of the superstructure. At the same time, the mechanical properties of the isolators must be accurately evaluated by means of adequate testing campaigns, which should be stretched beyond the qualification and acceptance protocols set in the reference Technical Standards, 


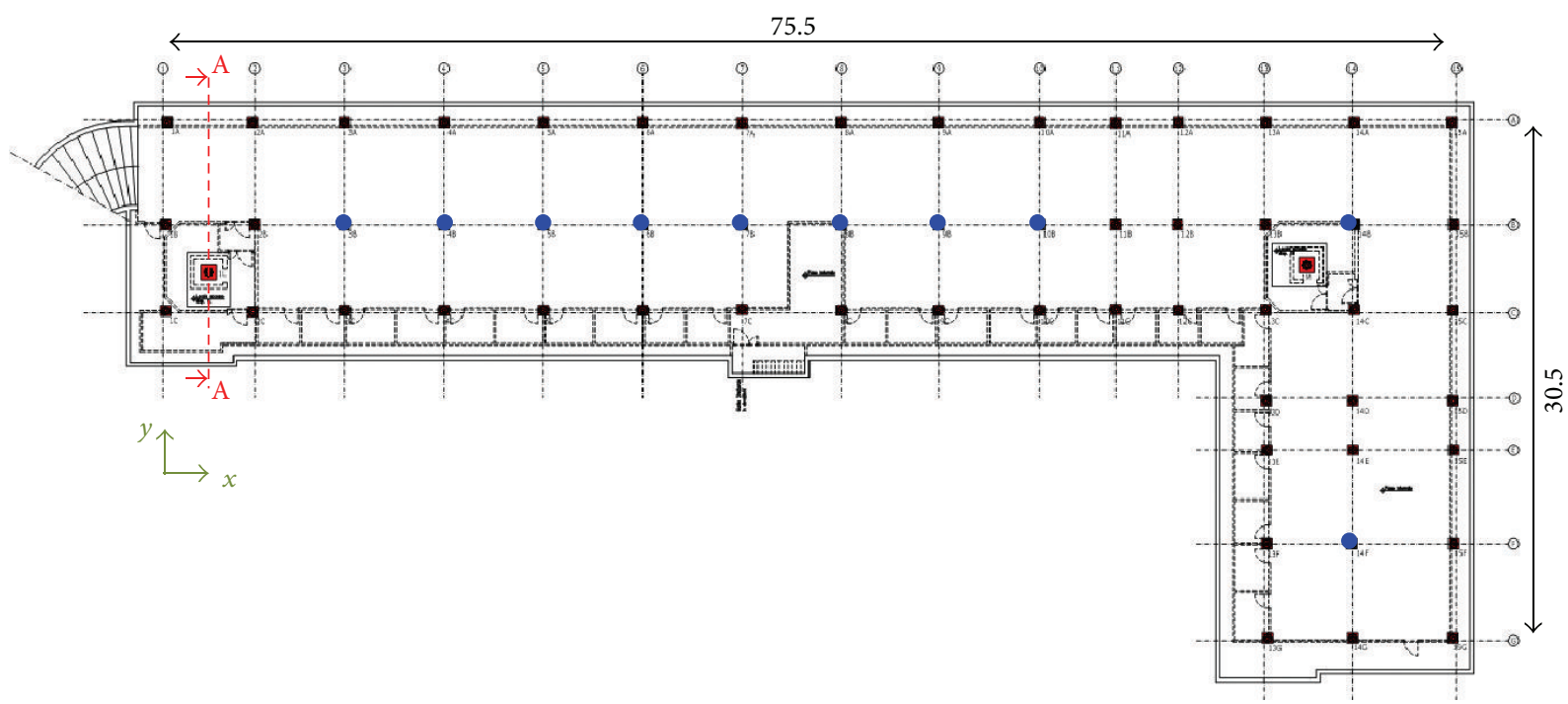

FIGURE 1: Basement plan of the building highlighting the positions of all 59 DFP isolators (squares: A-type; circles: B-type).
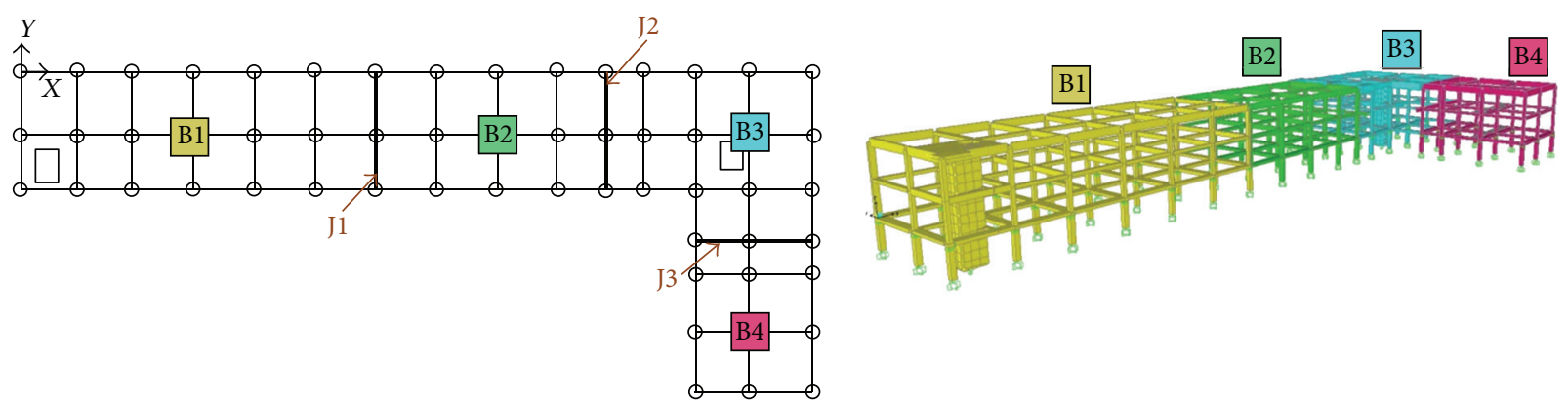

Figure 2: Numbering of the blocks (B1-B4) constituting the multiple building and relevant separation joints (J1-J3).

due to their strong influence on the response of a baseisolated structure.

A multiple residential building, well representative of the latest trends in the conception, analysis, and design of base-isolated structures mentioned above, is examined in this study. In particular, the following contents are presented in the next sections: the structural and dimensional characteristics of the building; the mechanical properties of the isolators, their experimental characterization, and preliminary sizing; the finite element model of the structure generated for the numerical study; the time-history design and performance assessment analyses carried out with normative-prescribed artificial accelerograms; a supplementary control of the response of the isolation system and the superstructure developed with highly demanding near-fault Italian real ground motions; technical details of installation of the isolators and illustrative images taken at the building site; and a summary of the construction costs.

\section{Structural Characteristics of the Building}

The building is situated in Sesto Fiorentino, a neighbour town to Florence, Italy. It is part of a subsidized public housing programme developed in the province of Florence and includes 26 flats to let of various dimensions. The reinforced concrete $(\mathrm{R} / \mathrm{C})$ structure was designed by the technical office of the local public authority owner of the building, based in Florence. The isolation system was designed by the second author of the paper, in cooperation with engineer Marco Zanfini, whose practice is based in Florence. The first author acted as tester of the structural works, whose images presented in Section 6 were taken during this institutional activity. All the results reported in the paper were obtained from independent analyses, elaborations, and verifications carried out by the authors, other than the ones developed for structural design.

Figure 1 shows the architectural plan of the basement level, where garages and cellars are accommodated. The building consists of a three-story $\mathrm{R} / \mathrm{C}$ frame structure, basement included, with interstory heights of $3.1 \mathrm{~m}$. The L-shaped plan has dimensions of about $75.5 \mathrm{~m}$ along the longitudinal direction, parallel to $x$-axis of the reference coordinate system in Figure 1, and $30.5 \mathrm{~m}$ in transversal direction, parallel to $y$, both measured from the outer sides of corner columns. The building is divided into four independent blocks, mutually separated by three thermal expansion joints. Blocks and joints are numbered in the schematic plan of the ground floor in Figure 2, where a $3 \mathrm{D}$ view of the finite element model of 


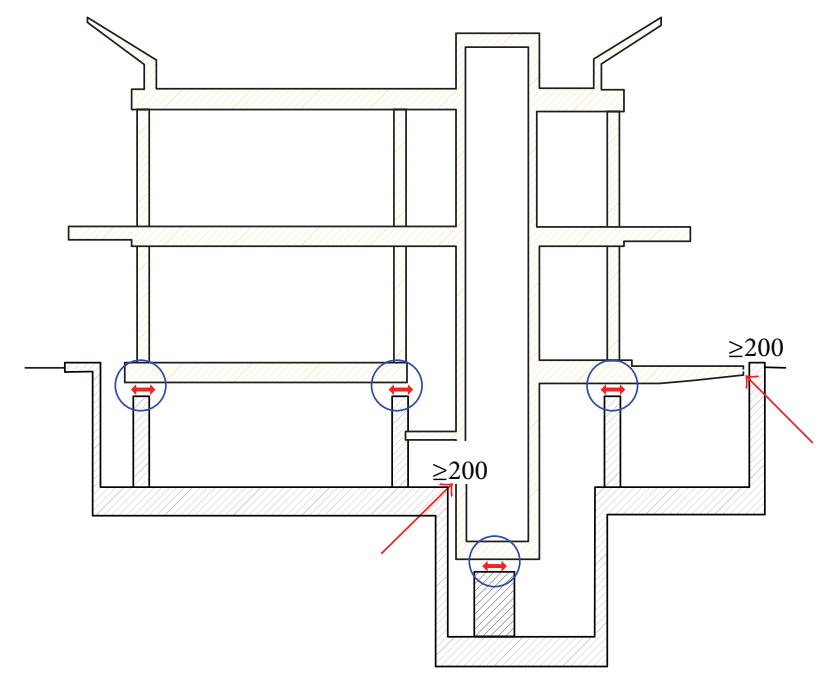

FIGURE 3: Schematic cross section in correspondence with the left elevator pit alignment, with isolators highlighted with circles and separation gaps between mobile and fixed structures with arrows.

the structural system, generated by a commercial calculus program, is also shown.

The structure of the floors and the roof is $280 \mathrm{~mm}$ thick and made of $230 \mathrm{~mm}$-high partly prefabricated Predallestype $\mathrm{R} / \mathrm{C}$ panels parallel to $y$, completed with a $50 \mathrm{~mm}$ thick on-site cast upper R/C slab. All beams have in-depth sections, with several different dimensions along $x$ and $y$. The columns have a mutual section of $(450 \times 450) \mathrm{mm} \times \mathrm{mm}$ on the basement story, and $(400 \times 300) \mathrm{mm} \times \mathrm{mm}$ on the ground and first story, with the largest side parallel to $x$, for the external alignments in plan, and parallel to $y$, for the internal ones. The dimensions and reinforcements of beams and columns are determined by the verifications at the ultimate limit states to gravitational loads only. The two box-shaped shear walls surrounding the elevator pits are $200 \mathrm{~mm}$ thick. The continuous perimeter retaining $\mathrm{R} / \mathrm{C}$ wall built around the structure allows easy access to the external side of the isolators of the perimeter columns for periodic inspection and maintenance activities. The internal columns can be directly accessed without any architectural obstruction.

Double friction pendulum (DFP) sliders, whose mechanical properties and experimental characterization are described in Section 4, were adopted as isolating devices. A total of 59 elements were incorporated, 57 of which on top of the basement columns and 2 below the bottom R/C slabs of the box-shaped structures surrounding the two elevator pits. Two types of DFP isolators were installed, only differing for their maximum admitted vertical load, equal to $1300 \mathrm{kN}$ (A devices) and $1600 \mathrm{kN}$ (B). The locations of the 49 A-type and 10 B-type elements are highlighted in Figure 1 with black squares and blue circles, respectively.

A schematic cross section of the building in correspondence with the left elevator pit alignment, named A-A in the plan of Figure 1, is drawn in Figure 3, illustrating the positions of the isolators along this line and particularly of the DFP slider placed below the bottom slab of the elevator pit. The width of the narrowest separation gaps between the mobile (filled in yellow) and fixed (dark brown) portions of the structural system, highlighted with red arrows, is no lower than $200 \mathrm{~mm}$, in order to accommodate the maximum attainable horizontal displacements of the base isolators discussed in the following sections.

Thanks to the mitigating action of base isolation, the foundation of the building is simply constituted by a continuous $650 \mathrm{~mm}$ high $\mathrm{R} / \mathrm{C}$ slab, reinforced with a top and bottom net of $\phi 16$ bars placed at a mutual distance of $200 \mathrm{~mm}$ along $x$ and $y$.

\section{Design Earthquake Levels and Seismic Performance Objectives}

The design of the building was carried out by referring to the four reference seismic levels fixed in the Italian Technical Standards [11], that is, frequent design earthquake (FDE, with $81 \%$ probability of being exceeded over the reference time period $V_{\mathrm{R}}$ ); serviceability design earthquake (SDE, with $50 \% / V_{\mathrm{R}}$ probability); basic design earthquake (BDE, with $10 \% / V_{\mathrm{R}}$ probability); and maximum considered earthquake (MCE, with $5 \% / V_{\mathrm{R}}$ probability). The $V_{\mathrm{R}}$ period was fixed at 50 years, which is obtained by multiplying the nominal structural life $V_{\mathrm{N}}$ of 50 years by a coefficient of use $c_{\mathrm{u}}$ equal to 1 , as prescribed for residential buildings in [12]. By referring to topographic category T1 (flat surface) and C-type soil (deep deposits of dense or medium-dense sand, gravel, or stiff clay from several ten to several hundred meters thick), the peak ground accelerations relevant to the four seismic levels for the municipality of Sesto Fiorentino are as follows: $0.073 \mathrm{~g}$ (FDE), $0.088 \mathrm{~g}$ (SDE), $0.203 \mathrm{~g}$ (BDE), and $0.251 \mathrm{~g}$ (MCE), with $g=$ acceleration of gravity.

Seven artificial accelerograms, that is, the minimum number fixed in the Italian Standards to offer statistical significance to the results of a dynamic analysis and to process them in mean terms, were generated from the elastic pseudoacceleration response spectra at linear viscous damping ratio $\xi=5 \%$, plotted in Figure 4, corresponding to the four reference seismic levels.

The design performance objectives for the building were fixed as follows: attaining operational (OP) performance level for FDE and SDE and immediate occupancy nonstructural (ION) level for BDE and MCE. Considering that infills are in contact with the frame structural members, OP and ION are met for values of the interstory drift ratio (i.e., the ratio of interstory drift to interstory height) limited below $0.33 \%$ and $0.5 \%$, respectively [11]. Both values implicitly guarantee totally undamaged response of infills and internal partitions, as well as of all structural members, and the first one of secondary finishes (plasters, tiles, etc.) too. The limits postulated for drifts also allow preventing pounding across the separation joints between the four blocks constituting the multiple building. The size of the joints was fixed at $50 \mathrm{~mm}$ in the architectural design for cosmetic reasons, also in view of the high performance in terms of interstory and total drifts targeted in the design, thanks to seismic isolation. The last design limitation concerns the base displacements of the mobile floor along both directions in plan, which must be 


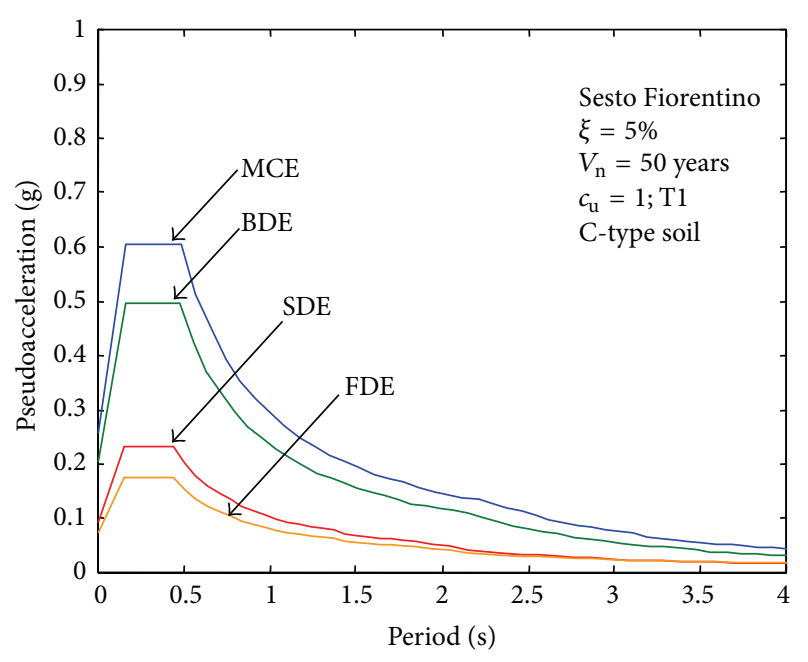

FIGURE 4: Normative pseudoacceleration elastic response spectra for Sesto Fiorentino-FDE, SDE, BDE, and MCE levels, $\xi=5 \%, V_{n}=50$ years, $c_{\mathrm{u}}=1$, topographic category $\mathrm{T} 1$, and C-type soil.

lower than the maximum attainable displacement, $d_{\max }$, of the DFP isolators.

It can be noted that these design objectives are extremely enhanced as compared to the ones assumed in the conventional ductility-based seismic design of fixed-base R/C structures. Indeed, the latter normally consists in a "diagonal" correlation [11, 12] between performance and earthquake levels, that is, ION level for FDE, with the $0.5 \%$ interstory drift ratio limitation defined above; immediate occupancy (IO) structural level for SDE, with the drift limit fixed at 1\%, according to the requirements of several Standards and Regulations, and corresponding moderate nonstructural damage, along with no appreciable structural damage; life safety (LS) level for BDE, with remarkable nonstructural damage, and moderate and diffused plasticizations of structural members; and collapse prevention (CP) for MCE, with very severe nonstructural damage, and severe structural plasticizations.

\section{DFP Sliders Selected for the Base Isolation System}

4.1. Mechanical Properties. Friction pendulum bearings, either with single [13], double [14], or triple [15, 16] sliding surfaces, are currently the most widely used isolation system worldwide. In fact, thousands of bearings are in service in several earthquake-prone countries, including Italy, where about 5000 single and about 2500 double friction pendulum devices have been installed in new apartment blocks built in L' Aquila after the severe earthquake that struck the city in 2009. However, most of these buildings are relatively small and regular in plan and elevation.

Double friction pendulum isolators have been proposed and implemented [14] with the aim of remarkably reducing dimensions and cost as compared to single friction pendulum devices designed for the same seismic performance. As shown in the left drawing in Figure 5, this is obtained by assembling two facing spherical concave surfaces, separated by an articulated double friction slider, which produce two independent pendulum response mechanisms, instead of one mechanism. This way, lateral deformation of the device is split between top and bottom surfaces, and thus the required plan diameter of each concave dish results in being significantly smaller than the diameter of the equivalent SFP isolator. Like for the other types of concave friction pendulum devices, DFP sliders have inherent recentering capacities.

The curvature radii of the spherical surfaces, $R_{1}$ and $R_{2}$, the distances from the center $\mathrm{P}$ of the articulated slider to the faces of the two surfaces, $h_{1}$ and $h_{2}$ (and thus the "effective pendulum lengths," that is, the distances from $\mathrm{P}$ and the centers of the surfaces, $R_{1}-h_{1}$ and $\left.R_{2}-h_{2}\right)$, and the friction coefficients, $\mu_{1}$ and $\mu_{2}$, of the two pendulum mechanisms may be selected independently, so as to achieve a trilinear force-displacement response relationship [14]. However, the standard DFP isolators currently available have equal radii $\left(R=R_{1}=R_{2}\right)$, slider center-to-surface face distances $(h=$ $h_{1}=h_{2}$, which means equal effective pendulum lengths, $\left.R-h=R_{1}-h_{1}=R_{2}-h_{2}\right)$, and friction coefficients $\left(\mu=\mu_{1}=\right.$ $\mu_{2}$ ) for the two surfaces, as indicated in the left and central drawings of Figure 5. This causes DFP devices in standard production-which can be defined as "symmetrical" DFP isolators for the properties above-to behave exactly like a single friction pendulum bearing, with $\mu$ friction coefficient and resulting in effective pendulum length $L_{\mathrm{DFP}}$ equal to twice the effective length relevant to each surface, that is, $L_{\mathrm{DFP}}=2 \cdot(R-h)=2 R-2 h[14]$.

The total reaction force of a DFP bearing, $F_{t}$, is given by the sum of the pendulum response component, $F_{\mathrm{p}}$, relevant to the isolation function and the friction component, $F_{f}$, governing the dissipative function. For symmetrical DFP isolators, $F_{\mathrm{p}}, F_{\mathrm{f}}$, and $F_{\mathrm{t}}$ have the following expressions, as derived from the classical theory of friction-damped pendulum [17]:

$$
\begin{gathered}
F_{\mathrm{p}}(t)=\frac{V(t)}{L_{\mathrm{DFP}}} d(t), \\
F_{\mathrm{f}}(t)=\mu V(t), \\
F_{\mathrm{t}}(t)=\frac{V(t)}{L_{\mathrm{DFP}}} d(t)+\mu V(t),
\end{gathered}
$$

with $d(t)=$ displacement and $V(t)=$ vertical force acting at the pivot point in seismic response conditions. It is noted that $V$ must be assumed as a function of time too, since it varies during seismic response, although slightly, due to a heavy reduction of earthquake loads on the superstructure determined by the filtering action of the base isolation system. Said $F_{\mathrm{t}, \max }$ the maximum value of $F_{\mathrm{t}}$, reached when $d_{\max }$ is achieved:

$$
F_{\mathrm{t}, \max }=\frac{\bar{V}}{L_{\mathrm{DFP}}} d_{\max }+\mu \bar{V}
$$

where $\bar{V}$ is the corresponding vertical force, the "linear equivalent" (or secant) stiffness of the isolator, $k_{\mathrm{e}}$, normally 

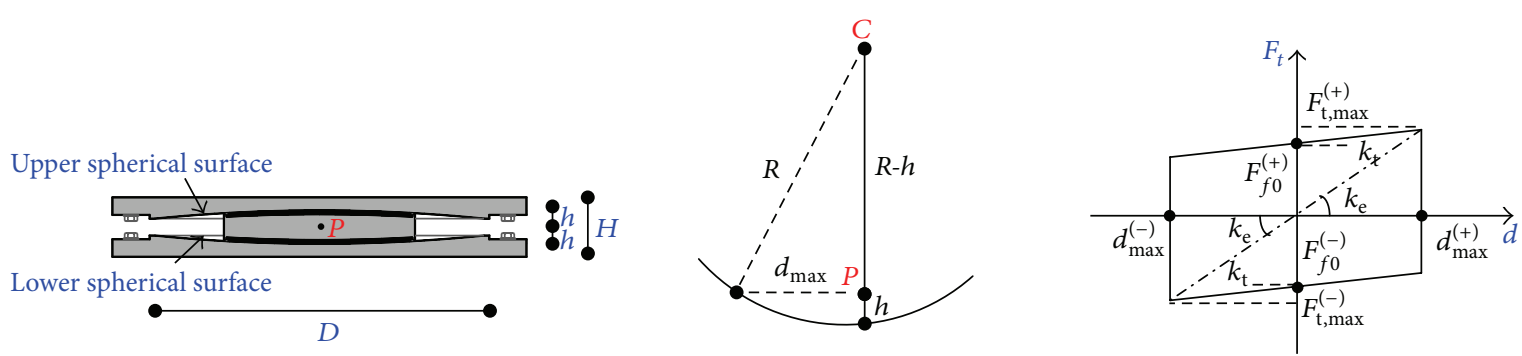

Figure 5: Cross section of a symmetrical DFP isolator, characterized by equal concave surfaces and friction coefficients, geometrical parameters of each spherical surface, and corresponding schematic $F_{\mathrm{t}}-d$ response cycle.

assumed as the conventional stiffness parameter in manufacturers' catalogues, is defined as follows:

$$
k_{\mathrm{e}}=\frac{F_{\mathrm{t}, \max }}{d_{\max }}=\left(\frac{1}{L_{\mathrm{DFP}}}+\frac{\mu}{d_{\max }}\right) \bar{V} .
$$

In order to quickly evaluate $k_{\mathrm{e}}$, in relation (5) $\bar{V}$ is fixed as the maximum value of the vertical force admitted in seismic response conditions, $V_{\max }$, provided in the manufacturers' catalogues too, as commented in Section 4.3. Based on the $k_{\mathrm{e}}$ expression above, the equivalent ("secant") vibration period of the isolator, $T_{e}$, is

$$
T_{\mathrm{e}}=2 \pi \sqrt{\frac{1}{g\left(1 / R+\mu / d_{\max }\right)}},
$$

with $g=$ acceleration of gravity. The equivalent viscous damping ratio, $\xi_{\mathrm{e}}$, is expressed as

$$
\xi_{\mathrm{e}}=\frac{2}{\pi} \cdot \frac{1}{d_{\max } / \mu R+1} .
$$

The values of $F_{\mathrm{p}}, F_{\mathrm{f}}, F_{\mathrm{t}}, F_{\mathrm{t} \text { max }}$, and $d_{\text {max }}$ must be intended both with positive and negative sign, as indicated in the schematised $F_{\mathrm{t}}-d$ cycle of a symmetrical DFP device traced out in the right image of Figure 5, where the mechanical parameters included in expressions (1) through (7) are highlighted. It is noted that in seismic response conditions the isolator follows the two sloped branches of the cycle, characterized by tangent stiffness $k_{\mathrm{t}}$, lower than $k_{\mathrm{e}}$. As a consequence, the actual ("tangent") vibration period ruling seismic response, $T_{\mathrm{t}}$, is greater than the conventionally defined equivalent period $T_{\mathrm{e}}$, which increases the benefits of base isolation to superstructure performance.

For the analyses carried out in this research and design study, the finite element model of DFP isolators was generated by a biaxial friction-pendulum with coupled friction properties for the deformations along the two reference local axes in plan, postslip stiffness in both directions, and "gap" type (i.e., no tension) behaviour in vertical direction. Friction and pendulum components act in parallel, with the former ruled by Wen hysteretic law [18] and the latter by the linear model formulated in [13].

4.2. Preliminary Sizing. The preliminary sizing of the isolators was carried out by estimating the maximum displacement demand for the MCE seismic level. This was obtained by referring to the normative MCE-scaled displacement spectrum for Sesto Fiorentino, for an equivalent viscous damping ratio $\xi_{\mathrm{e}}$ of about $15 \%$, corresponding-for $d_{\max }-$ to the standard friction coefficient $\mu=2.5 \%$ of DFP devices in standard production and a conventional $T_{\mathrm{e}}$ period greater than $2.5 \mathrm{~s}$, as assumed in the design of the base isolation system.

The MCE-scaled displacement spectrum is shown in Figure 6, for the basic equivalent viscous damping ratio $\xi=5 \%$ as well as for other values, including the $15 \%$ level above. The resulting spectral displacement for $\xi=15 \%$ and $T_{\mathrm{e}}>2.5 \mathrm{~s}, d_{\mathrm{d}, 0.15}$, is equal to about $115 \mathrm{~mm}$. It can be noted that this represents an overestimate of the maximum base displacement demand, because the actual $\xi$ value of the isolation system is greater than $\xi_{\mathrm{e}}$, as highlighted by relation (7), which can be used to evaluate $\xi$ too. Indeed, if the maximum base displacement computed from the final timehistory verification analysis, $d_{\mathrm{c}, \max }$, is substituted to $d_{\max }$, $\xi>\xi_{\mathrm{e}}$ is obtained, being $d_{\mathrm{c}, \max }<d_{\max }$. As discussed in Section 5, where the results of the time-history analyses are reported, $d_{c, \max }$ is equal to $91 \mathrm{~mm}$ in this case, and thus the corresponding $\xi$ coefficient is equal to about $26 \%$.

In the catalogue of the selected manufacturer, the smallest type of DFP isolators meeting the requirement of $d_{\mathrm{d}, 0.15}=$ $115 \mathrm{~mm}$ in terms of displacement capacities has the following mechanical and geometrical properties, in addition to $\mu=$ $2.5 \%: d_{\max }=200 \mathrm{~mm} ; L_{\mathrm{DFP}}=2535 \mathrm{~mm} ; T_{\mathrm{e}}\left(d_{\max }\right)=2.78 \mathrm{~s}$; $\xi_{\mathrm{e}}\left(d_{\max }\right)=15.3 \% ; D=430 \mathrm{~mm}$; and $H=$ height $=$ $89 \mathrm{~mm}$. The maximum admitted vertical force in seismic response conditions, $V_{\max }$, is equal to $1000 \mathrm{kN}$, greater than the highest design value, $V_{\mathrm{d}}$, estimated for the 49 A-type isolators in Figure 1, equal to about $900 \mathrm{kN}$. At the same time, $V_{\mathrm{d}}$ value is equal to about $1100 \mathrm{kN}$ for the $10 \mathrm{~B}$-type sliders. This demanded a small modification in the manufacturing of the internal slider, whose area was increased by $20 \%$, which allowed reaching a $V_{\max }$ value of $1300 \mathrm{kN}$ for B-type devices. All remaining geometrical and mechanical properties of Atype isolators, as listed above, were left unchanged for Btype elements. The maximum admitted vertical forces for gravitational loads at rest, $V_{\mathrm{Gr} \text { max }}$, are equal to $1300 \mathrm{kN}$ (A) and $1600 \mathrm{kN}$ (B). The corresponding design values, $V_{\mathrm{Gr}, \mathrm{d}}$, for the most demanding combination of dead and live gravitational loads at the ultimate limit state imposed by the Italian Technical Standards, equal to about $1100 \mathrm{kN}$ (A) and $1400 \mathrm{kN}(\mathrm{B})$, are absorbed safely too. 


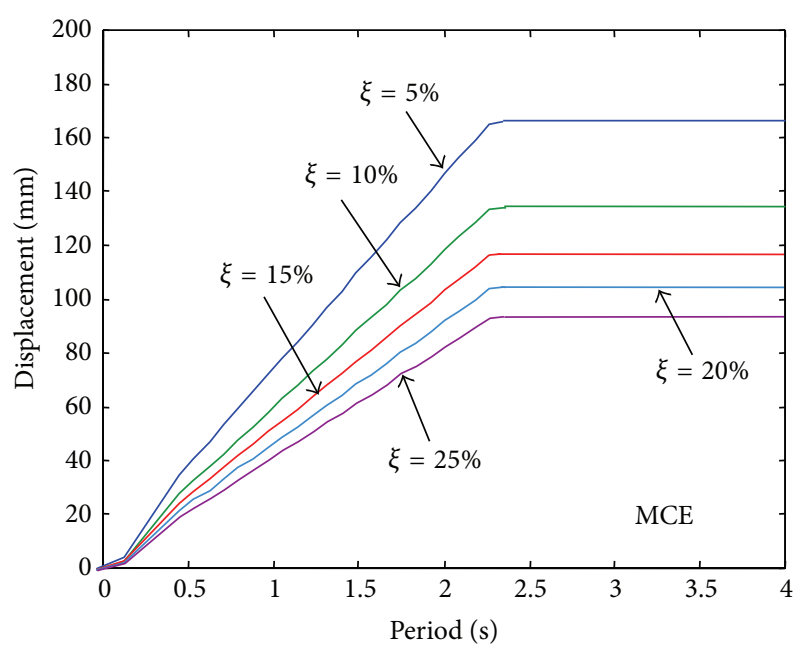

FIGURE 6: Normative displacement elastic response spectrum for Sesto Fiorentino-MCE level, $\xi=5 \%, 10 \%, 15 \%, 20 \%$, and $25 \%$, $V_{\mathrm{n}}=50$ years, coefficient of use $c_{\mathrm{u}}=1$, topographic category $\mathrm{T} 1$, and C-type soil.

4.3. Experimental Characterization Campaign. The experimental characterization programme was carried out on six Atype and six B-type isolators at the manufacturer's structural testing laboratory. The qualification and acceptance protocols of the Italian Technical Standards, which include several sets of quasistatic and dynamic tests, were thoroughly followed. Additional tests were developed, aimed at extending the variations ranges of the main testing parameters, namely, number of cycles, strain rate, and vertical force. In particular, the number of consecutive displacement cycles was fixed at ten in all tests, instead of five, as required by [11], in order to investigate any possible low-cycle fatigue and damage effects of the sliding surfaces of the isolators. Concerning strain rate, seven different testing velocities $v$ were imposed, equal to $0.1 \mathrm{~mm} / \mathrm{s}$ in the quasistatic test, and to $1,2.5,5,10,15$, and $20 \mathrm{~mm} / \mathrm{s}$ in the dynamic ones, so as to obtain a detailed friction coefficient-velocity curve. This allowed carefully tracing out, on an experimental basis, the corresponding analytical curve assigned in the finite element program to the "friction isolator" links simulating the response of DFP devices. The six dynamic tests were carried out with positive and negative displacement amplitude equal to the maximum base displacement computed from the time-history analyses, $d_{c, \max }=91 \mathrm{~mm}$. The vertical force was assumed as equal to the maximum design value $V_{\mathrm{d}}$ in all tests, except for the ones carried out at $10 \mathrm{~mm} / \mathrm{s}$ velocity, which were repeated with a force equal to $V_{\mathrm{d}} / 2$, to check the influence of this parameter too.

As a way of example of the results of the experimental campaign, Figures 7 and 8 show the response cycles and friction coefficient time-histories obtained from the tests performed on one A-type and one B-type isolator, with $d_{\mathrm{c}, \max }=$ $\pm 91 \mathrm{~mm}$ and $V_{\mathrm{d}}$ equal to $900 \mathrm{kN}-\mathrm{A}$ and $1100 \mathrm{kN}-\mathrm{B}$. The friction coefficient values plotted in the two time-history graphs were computed by means of (3), by substituting $V_{\mathrm{d}}$ to $V(t)$ and inserting the $F_{\mathrm{t}}(t)$ and $d(t)$ values measured at each step of the tests. Of course, the nominally negative $\mu$ values deriving from this calculation must be intended as absolute values (friction coefficient is a positive physical quantity).

The ten parallelogram-shaped cycles plotted in the left graphs of Figures 7 and 8 are totally superimposed, which indicates a stable and totally undamaged response of the thermoplastic material covering the two sliding surfaces of the DFP devices. The mean values of $\mu$ derived from the friction coefficient time-histories reproduced in the right graphs of the same Figures, highlighted with two red dotted segments, practically coincide with the nominal $2.5 \%$ value listed in the manufacturer's catalogue. This holds true for all ten displacement cycles, the first three of which are zoomed in the two graphs to enhance readability.

Figure 9 illustrates the friction coefficient-velocity curve obtained by interpolating the test points corresponding to the seven imposed velocities-highlighted with coloured dots-for the same A-type isolator to which Figure 7 makes reference. Beginning from a $\mu$ value of $2 \%$ derived from the quasistatic test at $v=0.1 \mathrm{~mm} / \mathrm{s}$, a short transient curved branch follows; afterwards, $2.5 \%$ "dynamic" value is reached for $v=5 \mathrm{~mm} / \mathrm{s}$ and then kept for $v=10 \mathrm{~mm} / \mathrm{s}$ and $v=20 \mathrm{~mm} / \mathrm{s}$. This sequence of experimental points shows a trend towards a steady horizontal branch for higher velocities, not applied in input during this campaign because of inherent limitations in the testing apparatus. Virtually coinciding curves were found for the remaining A-type and B-type isolators. This response is typical $[8,19]$ of the devices with thermoplastic sliding surfaces subjected to the lubrication processes requested by the reference Standards for antiseismic device manufacturing [20]. Indeed, these processes allow overcoming the remarkable influence of velocity on $\mu$ highlighted in earlier studies on nonlubricated sliders [21].

Concerning vertical force, a $\mu$ value of about $2.75 \%$ was computed from the results of tests with $V_{\mathrm{d}} / 2$ at $10 \mathrm{~mm} / \mathrm{s}$ velocity, with $10 \%$ increase as compared to the basic tests carried out with $V_{\mathrm{d}}$. Hence, the friction coefficient proved to be an inverse function of vertical force, as demonstrated by earlier research testing campaigns on isolators with thermoplastic sliding surfaces $[8,20]$. At the same time, the influence of vertical force is rather limited within the range of technical interest for this design, where $V_{\mathrm{d}} / 2$ represents the lowest threshold for any possible load combinations.

\section{Final Verification and Seismic Performance Assessment Analyses}

The final verification time-history analyses carried out at the FDE, SDE, BDE, and MCE normative earthquake levels confirmed the attainment of the design performance objectives postulated in Section 3. This is demonstratively illustrated by the graphs in Figure 10, which include plotting of the highest interstory drift ratio time-histories obtained for the most deformable story of the multiple building, that is, the second story of B2 block, the weakest direction of the superstructure in plan, $y$, and the most demanding among the seven input accelerograms scaled at the SDE and MCE amplitudes; and the force-displacement response cycles of the most stressed 

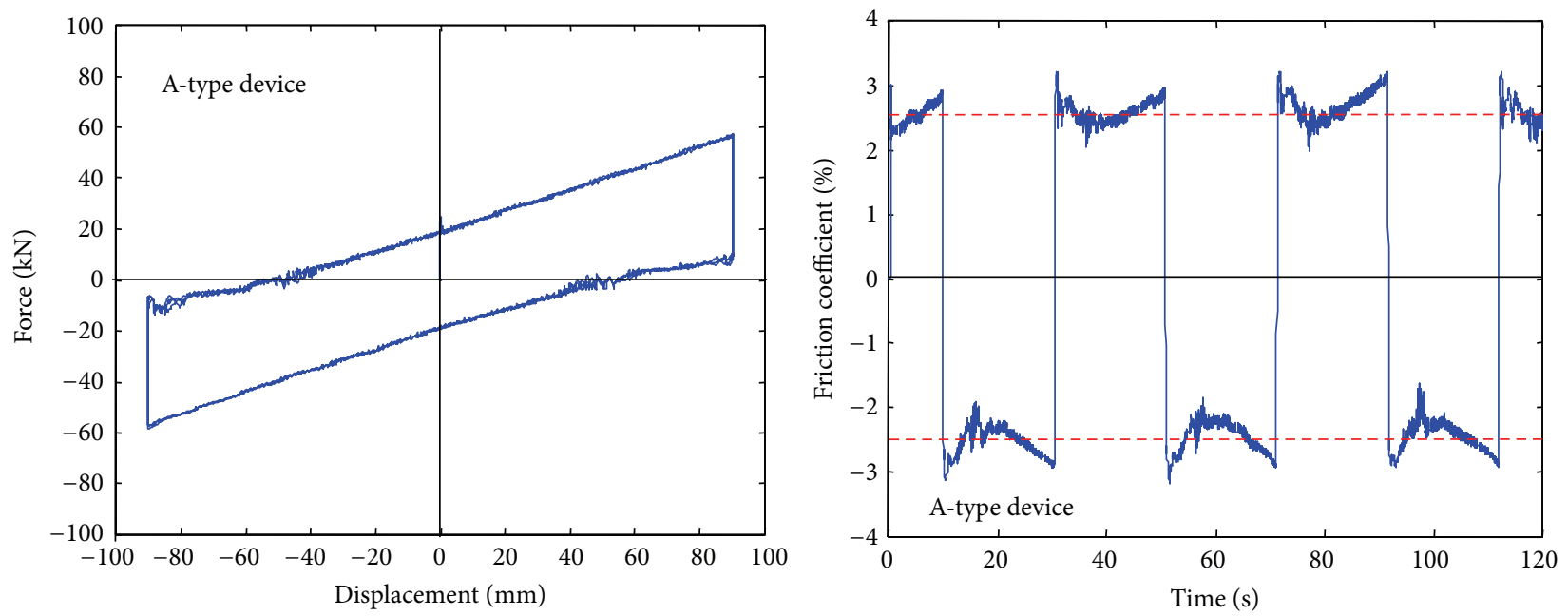

FIGURE 7: Response cycles and portion of the friction coefficient time-history obtained from a dynamic test carried out on one A-type isolator, with $d_{\mathrm{c}, \max }= \pm 91 \mathrm{~mm}, v=10 \mathrm{~mm} / \mathrm{s}$, and $V_{\mathrm{d}}=900 \mathrm{kN}$.
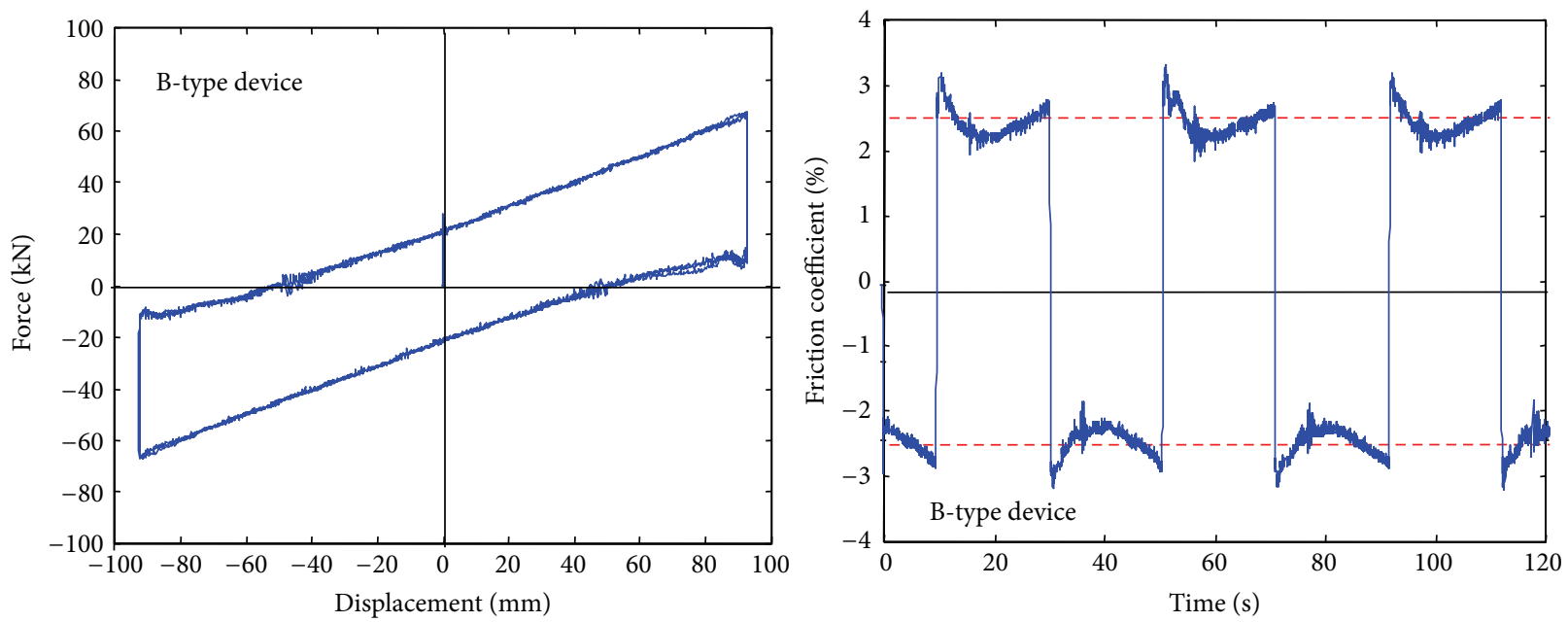

FIGURE 8: Response cycles and portion of the friction coefficient time-history obtained from a dynamic test carried out on one B-type isolator, with $d_{c, \max }= \pm 91 \mathrm{~mm}, v=10 \mathrm{~mm} / \mathrm{s}$, and $V_{\mathrm{d}}=1100 \mathrm{kN}$.

isolator (A-type, situated on the upper right corner in plan of B3 block), again along $y$, derived from the same MCE-scaled input motion.

The peak values of the time-histories for SDE and MCE are lower than $0.33 \%$ limit drift ratio assumed for OP performance level (highlighted with two dotted segments in the left graph of Figure 10) and 0.5\%, postulated for ION, respectively. This means that the targeted SDE-OP and MCEION design performance objectives are met and thus FDEOP and BDE-ION objectives too, since FDE is less demanding than SDE and BDE than MCE. The maximum drifts of B2 block along $x$ are $10 \%$ lower than along $y$. The resulting maximum second story total displacement at MCE in $x$, which is the potential pounding direction, is equal to $24 \mathrm{~mm}$, that is, less than half the separation gap width of $50 \mathrm{~mm}$ adopted for the three technical joints of the multiple building. The peak top displacements of the remaining blocks are lower than B2 ones. Additional data deducted from the analyses are represented by the fundamental vibration periods of the building, which result to be equal to $3.12 \mathrm{~s}$ along $x$ and $3.15 \mathrm{~s}$ along $y$, as determined by the "tangent" periods $T_{\mathrm{t}}$ of the two sets of isolators in seismic response conditions. The cycles of the most stressed isolator plotted in the right graph of Figure 10, referred to $y$-axis too, are nearly coinciding with the cycles computed along $x$. The peak displacement $d_{c, \max }$ of $91 \mathrm{~mm}$ (equal to $90.2 \mathrm{~mm}$ in $x$ direction), already mentioned in Sections 4.2 and 4.3, is less than half $d_{\max }$, thus meeting with large safety margins the requirement for base displacements at MCE. As noted in Section 4.2, the equivalent viscous damping ratio of the isolation system corresponding to $d_{c, \max }$ is equal to about $26 \%$.

In the final verification phase, a supplementary control on the response of the isolation system was carried out by developing a further set of time-history analyses, where 


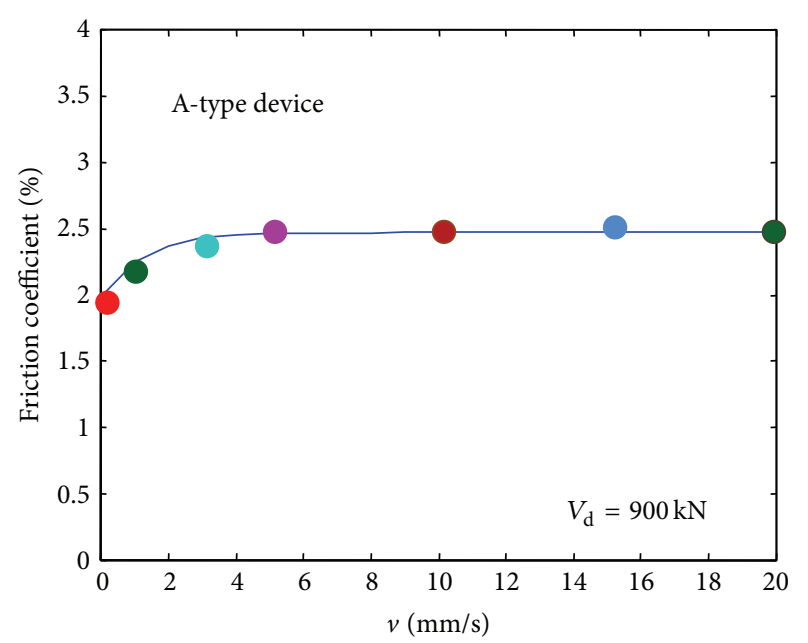

FIGURE 9: Friction coefficient values as a function of $v$-A-type isolator, $V_{\mathrm{d}}=900 \mathrm{kN}$.

several near-fault real ground motions recorded during the greatest earthquakes in Italy over the past thirty years were taken as inputs, in order to produce highly demanding response conditions for the base isolated building. The faultnormal N-S main shock component recorded in L' Aquila on April 6, 2009 (03:32 a.m.) at the Parking seismographic station downtown, whose pseudoacceleration and displacement elastic response spectra at $5 \%$ viscous damping ratio are plotted in Figure 11, proved to be the most demanding ground motion.

This component, named AQK in the record database of L' Aquila earthquake, is characterized by a distance of $5.6 \mathrm{~km}$ from the surface projection of the causative fault, moment magnitude $M_{\mathrm{w}}=6.3$, and peak ground acceleration of $0.353 \mathrm{~g}$, that is, $40 \%$ greater than the value of the MCE-scaled normative seismic action. Due to the near-fault characteristics of the AQK motion record, the spectral displacements at $\xi=5 \%$ are about $40 \%$ greater than the corresponding values for MCE too, for vibration periods around the fundamental periods of $3.12 \mathrm{~s}$ and $3.15 \mathrm{~s}$ of the isolated building along the two axes in plan.

The results of this additional set of analyses are summarized in Figure 12, where the response graphs presented in Figure 10 above for the most demanding normative accelerogram and $y$ direction, are plotted for the AQK input motion too. The second interstory drift ratio time-history for B2 block displayed in the left graph shows that only one pulsetype peak, equal to $0.74 \%$, exceeds the limit of $0.5 \%$ assumed for ION performance level, whereas the remaining portion of response remains below this limit. This means that immediate occupancy structural performance level is guaranteed, as identified by a drift ratio limit of $1 \%$. The maximum second story total displacement in $x$ is equal to $37 \mathrm{~mm}$, that is, still below the thermal expansion joint width of $50 \mathrm{~mm}$.

The response cycles show a maximum displacement of $168 \mathrm{~mm}, 16 \%$ lower than the maximum attainable displacement of the isolators, recorded at the same instant in which the pulse-type peak drift of the superstructure, typical of near-fault real ground motions, is reached. In fact, as suggested by several international Standards and Recommendations, this supplementary control was performed because one or more pulses can occasionally exceed the displacement capacity of a base isolated structure and/or induce high drift demands on the superstructure, even for near-fault earthquakes that are moderately demanding in terms of magnitude, peak ground acceleration, and energy content, as the considered $\mathrm{AQK}$ component.

\section{Design Details and Highlights of Construction Works}

The technical installation details of the isolators are illustrated in the drawings of Figure 13 and the photographic sequence of Figure 14. Four internally threaded cylindrical steel caps supplied by the manufacturer are fixed with steel bolts to the lower plate of the DFP device prior to initialising its installation. The caps are fitted in four holes arranged in the cast of the R/C column capital by means of PVC pipes. Afterwards, the holes are filled with high-strength hyperfluid mortar, injected by means of a pressurized pump, which is also cast below the intrados of the isolator, so as to obtain a perfectly planar bearing bed. Four more caps are then screwed to the upper plate of the device, in order to be embedded in the cast of the $\mathrm{R} / \mathrm{C}$ beam of the mobile ground floor, built at a following step of the construction works. This mounting solution allows easy removal of the isolator for any possible future testing check or replacement, as required by the periodic maintenance and control plan prescribed by the Italian Technical Standards. Removal is carried out with the following three steps: (1) unscrewing the eight bolts from the cylindrical caps, (2) uplifting by $4-5 \mathrm{~mm}$ the upper R/C beam of the ground floor by means of vertical hydraulic actuators introduced between the extrados of the column capital and the intrados of the beam, and (3) shifting the device out of the capital. The actuators are temporarily left in place until the isolator (or an identical one, in case it needs replacing) is repositioned. The beam, capital, and column sections and reinforcements are designed so as to safely absorb the stress states induced by the uplift forces applied to remove the device, in addition to the stress states deriving from the most demanding design combinations of dead and live loads.

Other photographic images referred to the characteristic construction details of this design are offered in Figures 15 through 18. Figure 15 shows views of the isolator placed below the bottom R/C slab of one of the two elevators and the devices situated along one of the main beams (parallel to $x$ ), with their four top cylindrical caps screwed to the upper plate, prior to installing the reinforcing bars of the beam and the concrete cast.

Figure 16 illustrates the flexible joints installed on gas pipes at an interface area between the mobile and fixed portions of the building. These joints, capable of accommodating the maximum attainable displacement of the isolators $d_{c, \max }= \pm 200 \mathrm{~mm}$, are in current production and involve no additional costs as compared to the conventional joints mounted in standard fixed-base buildings. 

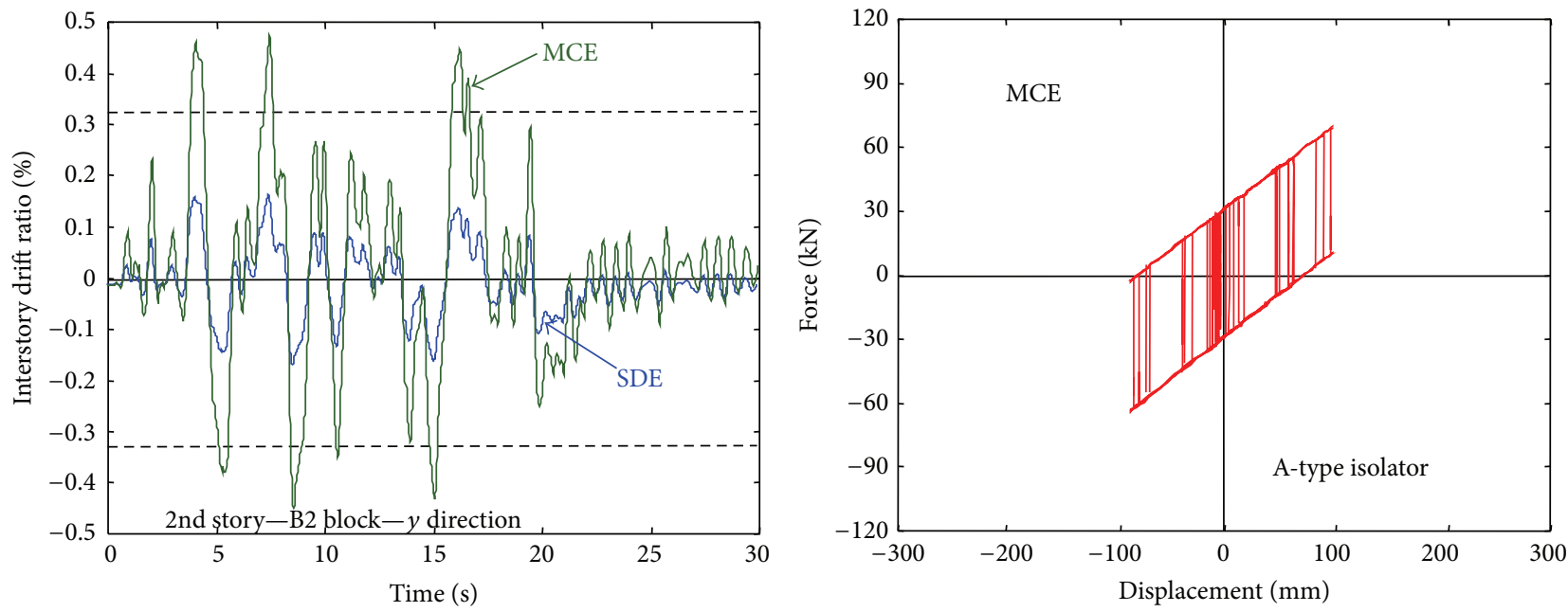

FIGURE 10: Second interstory drift ratio time-histories for B2 block and response cycles of most stressed DFP isolator obtained in $y$ direction from the most demanding MCE-scaled input accelerogram.
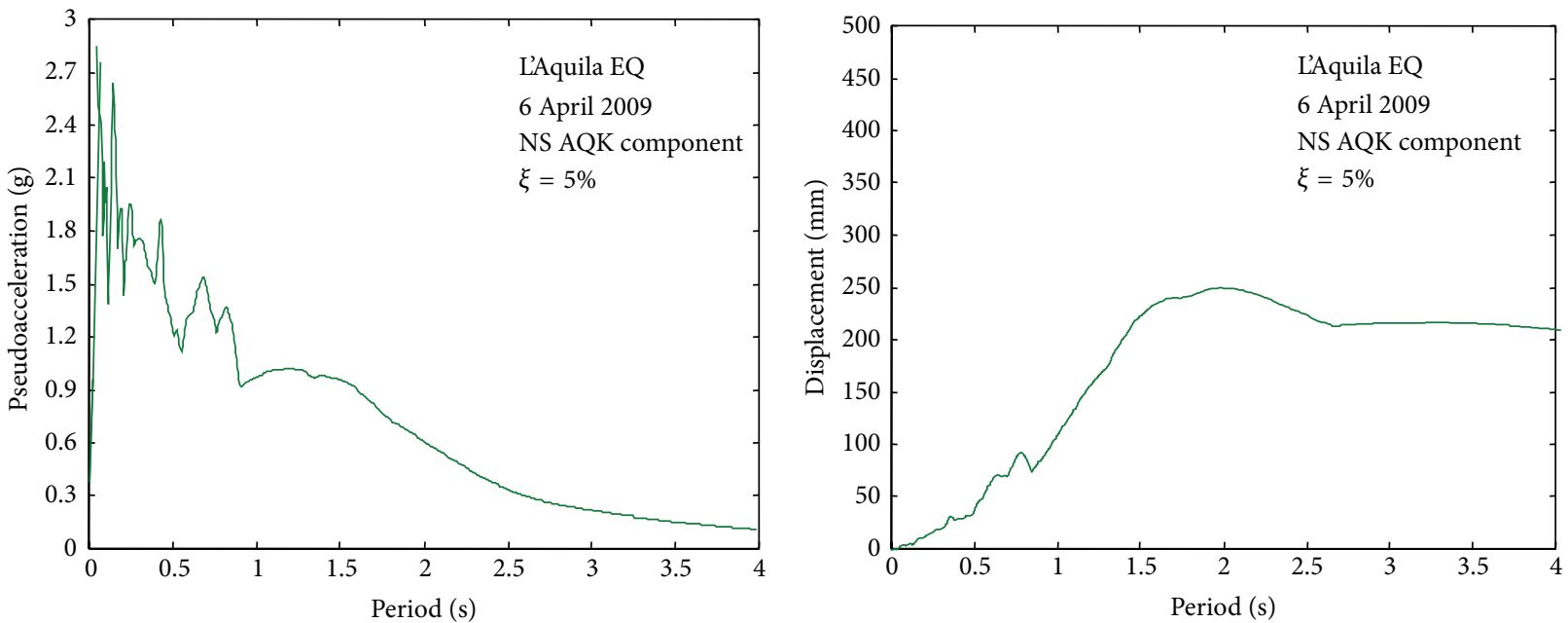

FIGURE 11: Pseudoacceleration and displacement elastic response spectra at $\xi=5 \%$ of NS AQK component-L' Aquila earthquake of 6th of April 2009.

Figure 17 shows the waste water pipes at another interface area and two columns before and after the installation of a fire-protection plasterboard around the isolator on top. Views of a wing of the perimeter interspace between the retaining wall of the basement and the building, the thermal expansion joint between B2 and B3 blocks, with relevant covering buttstrap, and the main façades of B1 through B3 blocks (third image from the left) and B4 block (fourth image), with a "brise soleil" finishing system installed at the end of the construction works, are presented in Figure 18.

A final observation concerns the cost of the building structure, equal to about 920,000 Euros, isolation system included. This amount is $15 \%$ lower than the cost of a conventional fixed-base seismic design of the R/C structure, equal to 1,080,000 Euros, which was estimated to offer a price comparison to the customer. The conventional ductilitybased design, targeting the basic "diagonal" correlation between performance and earthquake levels mentioned in Section 3 (ION-FDE, IO-SDE, LS-BDE, CP-MCE) requires incorporating ten additional $\mathrm{R} / \mathrm{C}$ walls, as well as providing greater sections and reinforcements of columns, beams, and foundations.

\section{Conclusions}

The base isolation solution adopted for the multibody residential building presented in this paper allowed reaching the very high performance objectives targeted in its design with small-sized double friction pendulum devices. In addition to far greater seismic performance, smaller sized R/C members, and correspondingly reduced architectural intrusion of the structural system, the isolation system also guarantees $15 \%$ reduction in costs, as compared to a conventional fixedbased design, developed to establish a price comparison for 

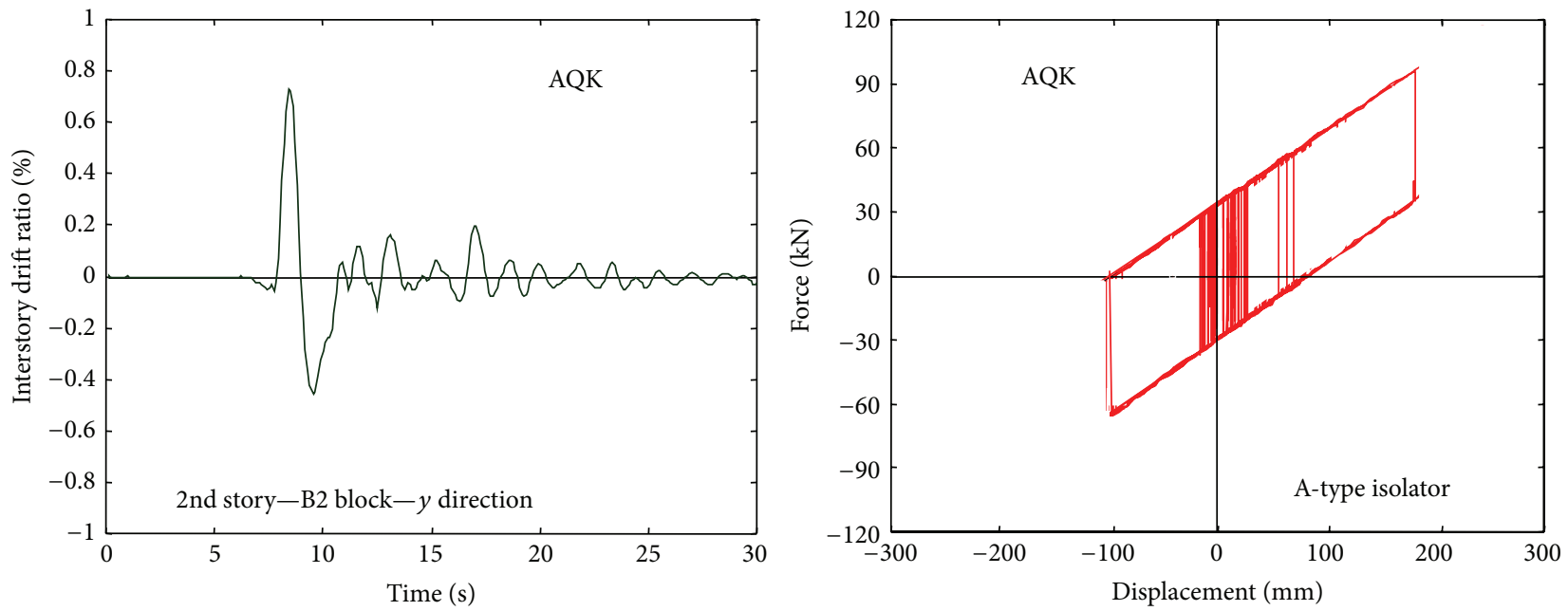

FIGURE 12: Second interstory drift ratio time-histories for B2 block and response cycles of most stressed DFP isolator obtained in $y$ direction from the NS AQK input accelerogram.
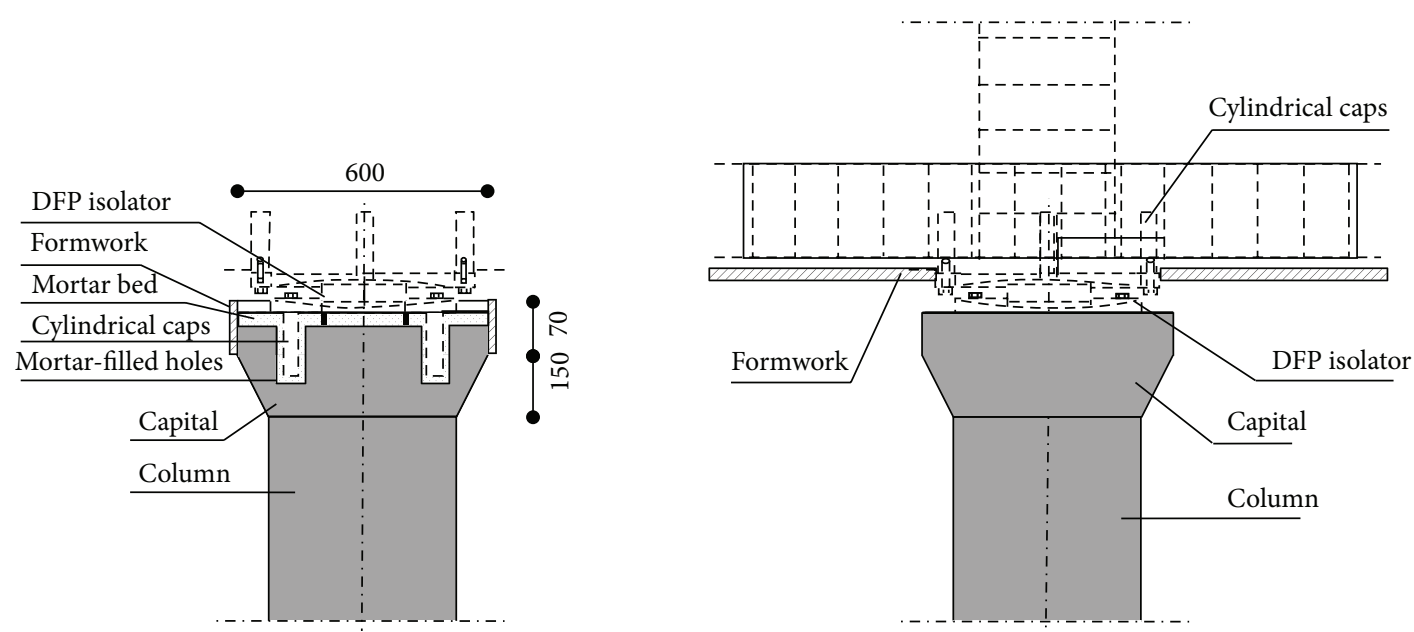

FIGURE 13: Design drawings concerning the installation details of a DFP isolator over a column.
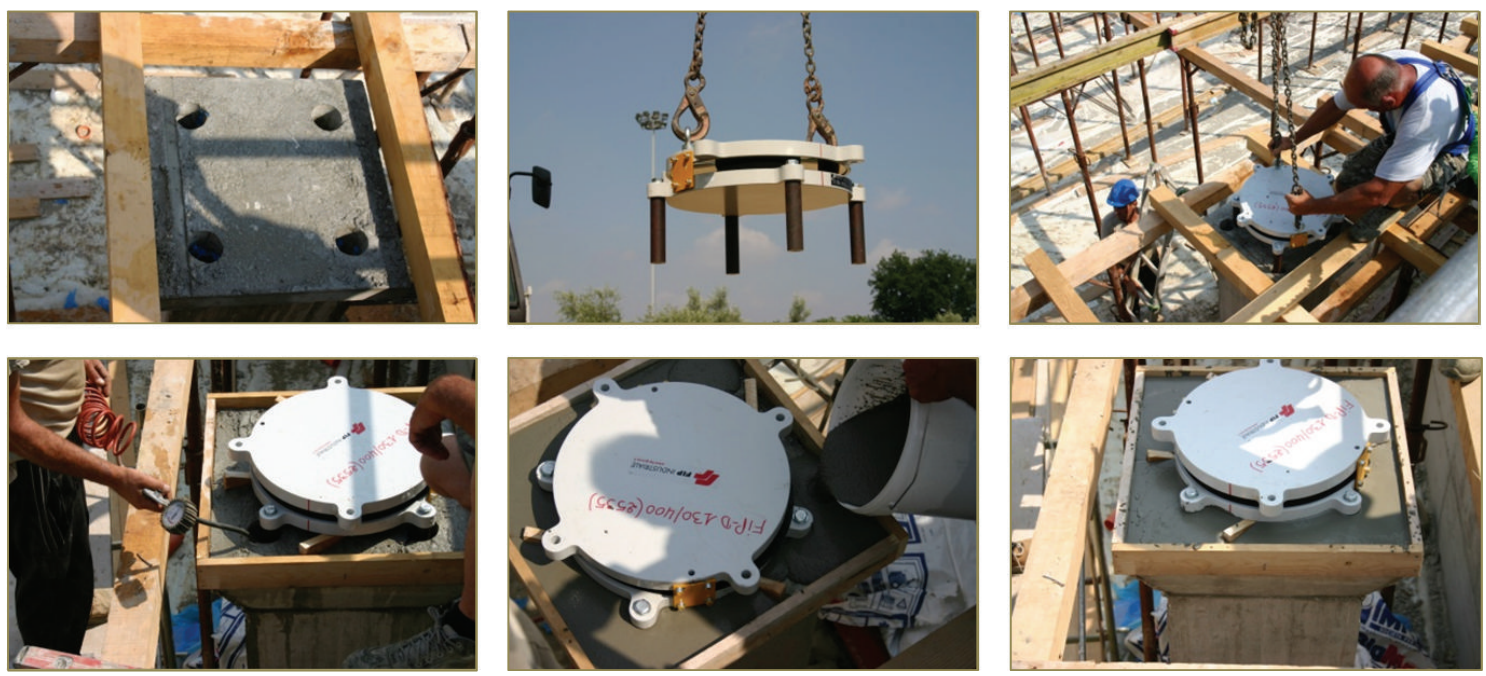

FIGURE 14: Images of the installation works of a DFP isolator over a column. 

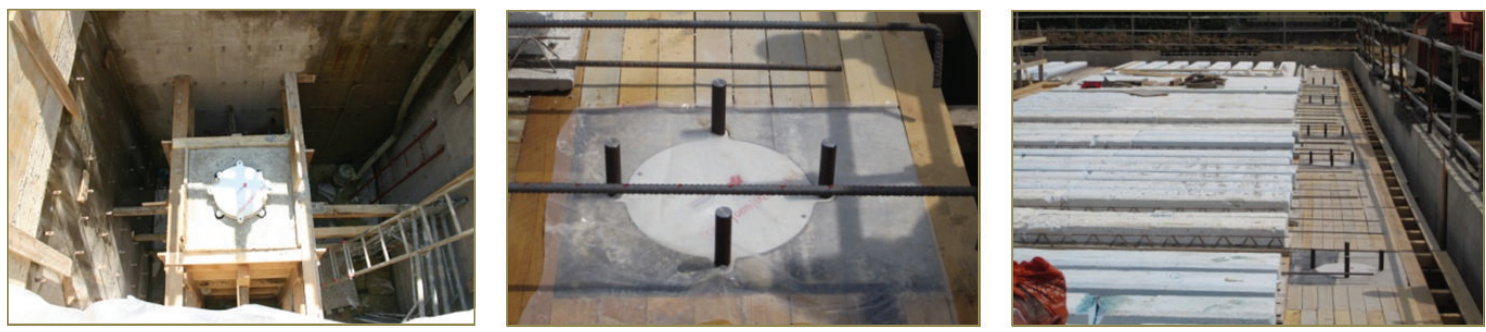

FIGURE 15: Images of the installation works of a DFP isolator placed below the bottom R/C slab of an elevator (left) and some isolators with the top cylindrical caps screwed before casting the relevant upper R/C beam.
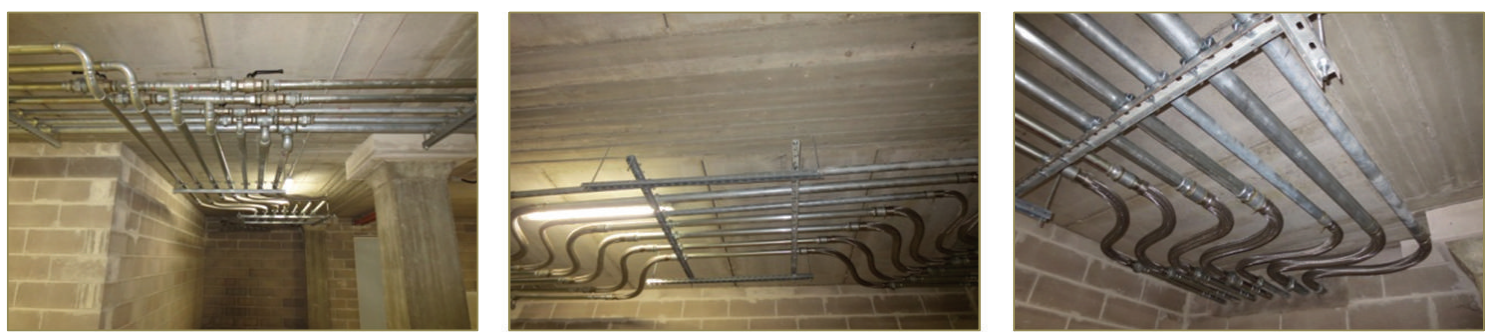

FIGURE 16: Images of gas pipes at an interface area between the mobile and fixed portions of the building.
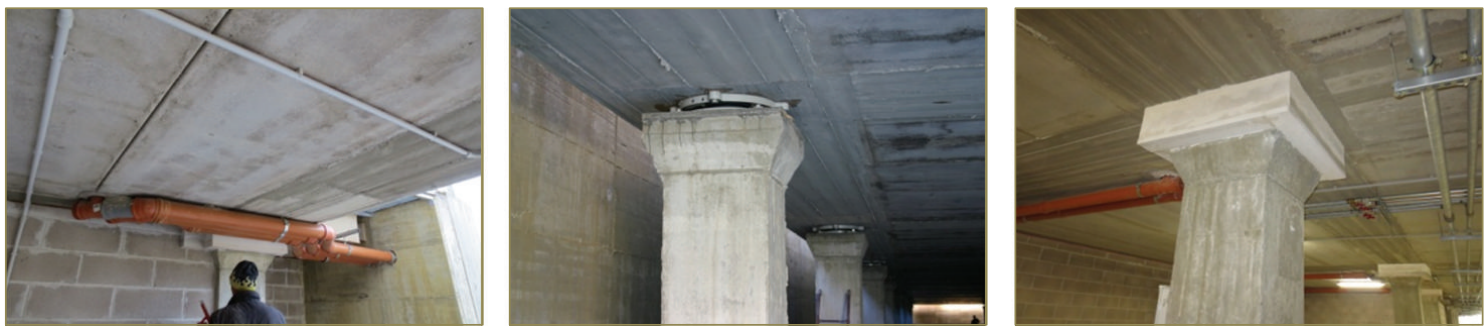

FIGURE 17: Images of waste water pipes at an interface area between the mobile and fixed portions of the building and two columns before and after the installation of the fire-protection plasterboard on the isolators.
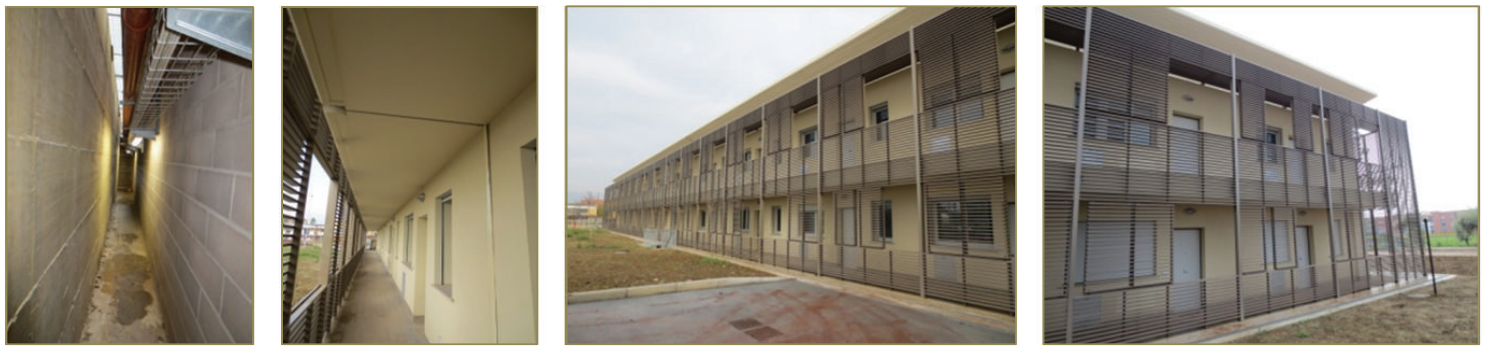

FIGURE 18: Images of a wing of the perimeter interspace between the retaining wall of the basement and the building, the thermal expansion joint between B2 and B3 blocks, and the main façades of B1-B3 and B4 blocks.

the customer. Specific remarks deriving from the results of the experimental characterization campaign carried out on the isolators, and the performance assessment analyses and design studies developed on the building structure, are reported below.

(i) Base isolation practically allowed sizing the sections of columns, beams, and foundations to gravitational loads only. The reinforcement details were notably simplified too, as compared to the conventional ductility-based fixed-base seismic design, which helped reduce the cost of the R/C structure by about 300,000 Euros.

(ii) The total cost of the isolation system, testing campaign, installation works, and fire protection of DFP devices included amounts to about 140,000 Euros, with a net saving of 160,000 Euros off the total cost of the structural system.

(iii) The testing programme carried out on a set of six A-type and six B-type isolators revealed a stable 
and totally undamaged response of the thermoplastic material covering the two sliding surfaces of DFP devices, even after repetition of 80 cycles at different deformation velocities.

(iv) The strain-rate influence is limited to the smallest testing velocities (below $5 \mathrm{~mm} / \mathrm{s}$ ), for which $\mu$ increases from $2 \%$, as derived from the quasistatic tests, to $2.5 \%$. For increasing velocities, a trend towards a steady horizontal branch of the $\mu-v$ experimental curve is observed, as typical of several classes of sliders with lubricated thermoplastic surfaces.

(v) In all tests with $v \geq 5 \mathrm{~mm} / \mathrm{s}$, the mean values of the friction coefficient always coincide with the nominal $2.5 \%$ value listed in the manufacturer's catalogue.

(vi) The extremely enhanced performance objectives met thanks to base isolation (FDE-OP, SDE-OP, BDEION, MCE-ION), in comparison to the standard objectives typically targeted in comparative fixedbase design (FDE-ION, SDE-IO, BDE-LS, MCE-CP), allow also reducing the total top displacements of the four blocks below the narrow width of their mutual separation joints. This very limited gap width gives the structure the appearance of a single building, in accordance with the most recent trends of the architectural design of "artificial ground" construction.

(vii) The frictional response of DFP sliding bearings allows restraining base displacements within limits being consistent with the adoption of simple flexible joints for the gas, water, and drain ducts crossing the ground floor.

(viii) In addition to the standard verification analyses at the MCE carried out with a set of normative accelerograms, base displacement demand was also successfully checked by means of a supplementary timehistory investigation developed with the real nearfault NS AQK component of 2009 L' Aquila earthquake as input. The response of the superstructure was positively checked too, showing only a single peak interstory drift greater than the maximum drifts computed with the most demanding MCE-scaled input accelerogram. The AQK peak drift meets the requirements of the IO performance level, instead of the ION level guaranteed by the response to normative ground motions.

\section{Conflict of Interests}

The authors declare that there is no conflict of interests regarding the publication of this paper.

\section{Acknowledgment}

The section of study dedicated to the mechanical characterization and numerical modelling of the DFP isolators was financed by the Italian Department of Civil Protection within the ReLUIS-DPC Project 3-2014/2016. The authors gratefully acknowledge this financial support.

\section{References}

[1] A. Martelli and M. Forni, "Seismic isolation and other antiseismic systems. Recent applications in Italy and worldwide," Seismic Isolation and Protective Systems, vol. 1, no. 1, pp. 75-123, 2010.

[2] L. Di Sarno, E. Chioccarelli, and E. Cosenza, "Seismic response analysis of an irregular base isolated building," Bulletin of Earthquake Engineering, vol. 9, no. 5, pp. 1673-1702, 2011.

[3] S. Sorace and G. Terenzi, "Analysis and demonstrative application of a base isolation/supplemental damping technology," Earthquake Spectra, vol. 24, no. 3, pp. 775-793, 2008.

[4] S. Sorace and G. Terenzi, "Motion control-based seismic retrofit solutions for a R/C school building designed with earlier technical standards," Bulletin of Earthquake Engineering, 2014.

[5] F. Mazza and A. Vulcano, "Effects of near-fault ground motions on the nonlinear dynamic response of base-isolated r.c. framed buildings," Earthquake Engineering \& Structural Dynamics, vol. 41, no. 2, pp. 211-232, 2012.

[6] F. Mazza, M. Mazza, and A. Vulcano, "Nonlinear dynamic response of RC buildings with different base-isolation systems subjected to horizontal and vertical components of near-fault ground motions," The Open Construction \& Building Technology Journal, vol. 6, pp. 373-383, 2012.

[7] V. K. Agarwal, J. M. Niedzwecki, and J. W. van de Lindt, "Earthquake induced pounding in friction varying base isolated buildings," Engineering Structures, vol. 29, no. 11, pp. 2825-2832, 2007.

[8] S. Sorace, G. Terenzi, G. Magonette, and F. J. Molina, "Experimental investigation on a base isolation system incorporating steel-teflon sliders and pressurized fluid viscous spring dampers," Earthquake Engineering and Structural Dynamics, vol. 37, no. 2, pp. 225-242, 2008.

[9] D. Foti, A. C. Goni, and S. Vacca, "On the dynamic response of rolling base isolation systems," Structural Control and Health Monitoring, vol. 20, no. 4, pp. 639-648, 2013.

[10] P. J. Sayani, E. Erduran, and K. L. Ryan, "Comparative response assessment of minimally compliant low-rise base-isolated and conventional steel moment-resisting frame buildings," Journal of Structural Engineering, vol. 137, no. 10, pp. 1118-1131, 2011.

[11] Italian Council of Public Works, Technical Standards on Constructions, Italian Council of Public Works, Rome, Italy, 2008, (Italian).

[12] American Society of Civil Engineers, Seismic Rehabilitation of Existing Buildings-ASCE/SEI 41-06, American Society of Civil Engineers, Reston, Va, USA, 2006.

[13] V. Zayas, S. Low, and S. Mahin, "A simple pendulum technique for achieving seismic isolation," Earthquake Spectra, vol. 6, no. 3, pp. 317-334, 1990.

[14] D. M. Fenz and M. C. Constantinou, "Behaviour of the double concave Friction Pendulum bearing," Earthquake Engineering \& Structural Dynamics, vol. 35, no. 11, pp. 1403-1424, 2006.

[15] D. M. Fenz and M. C. Constantinou, "Spherical sliding isolation bearings with adaptive behavior: theory," Earthquake Engineering and Structural Dynamics, vol. 37, no. 2, pp. 163-183, 2008.

[16] T. A. Morgan and S. A. Mahin, "Achieving reliable seismic performance enhancement using multi-stage friction pendulum isolators," Earthquake Engineering and Structural Dynamics, vol. 39, no. 13, pp. 1443-1461, 2010.

[17] L. Xue, Pendulum Systems, Seeing and Touching Structural Concepts, Civil Engineering Department, University of Manchester, Manchester, UK, 2007. 
[18] Y. K. Wen, "Method for random vibration of hysteretic system," Journal of the Engineering Mechanics Division, vol. 102, no. 2, pp. 249-263, 1976.

[19] M. Dolce, D. Cardone, and F. Croatto, "Frictional behavior of steel-PTFE interfaces for seismic isolation," Bulletin of Earthquake Engineering, vol. 3, no. 1, pp. 75-99, 2005.

[20] European Committee for Standardization, UNI EN 15129Anti-Seismic Devices, European Committee for Standardization, Bruxelles, Belgium, 2009.

[21] A. Mokha, M. C. Constantinou, and A. Reinhorn, "Teflon bearings in base isolation I: testing," ASCE Journal of Structural Engineering, vol. 116, no. 2, pp. 438-454, 1990. 

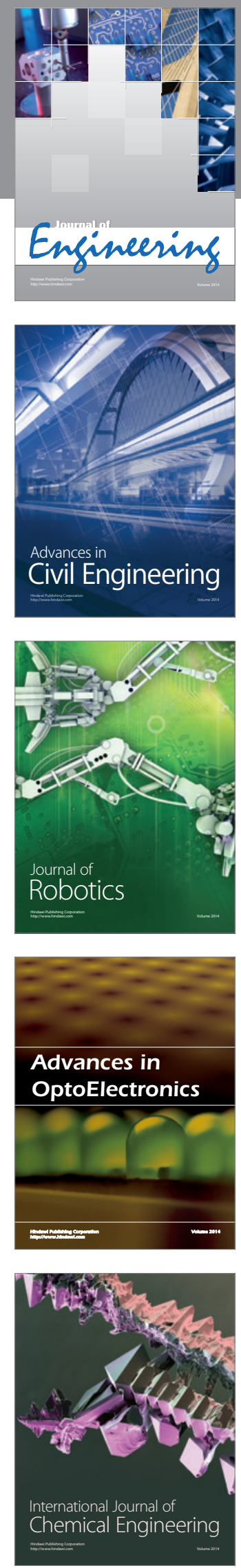

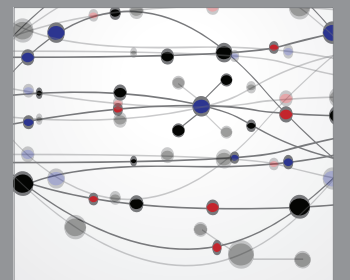

The Scientific World Journal
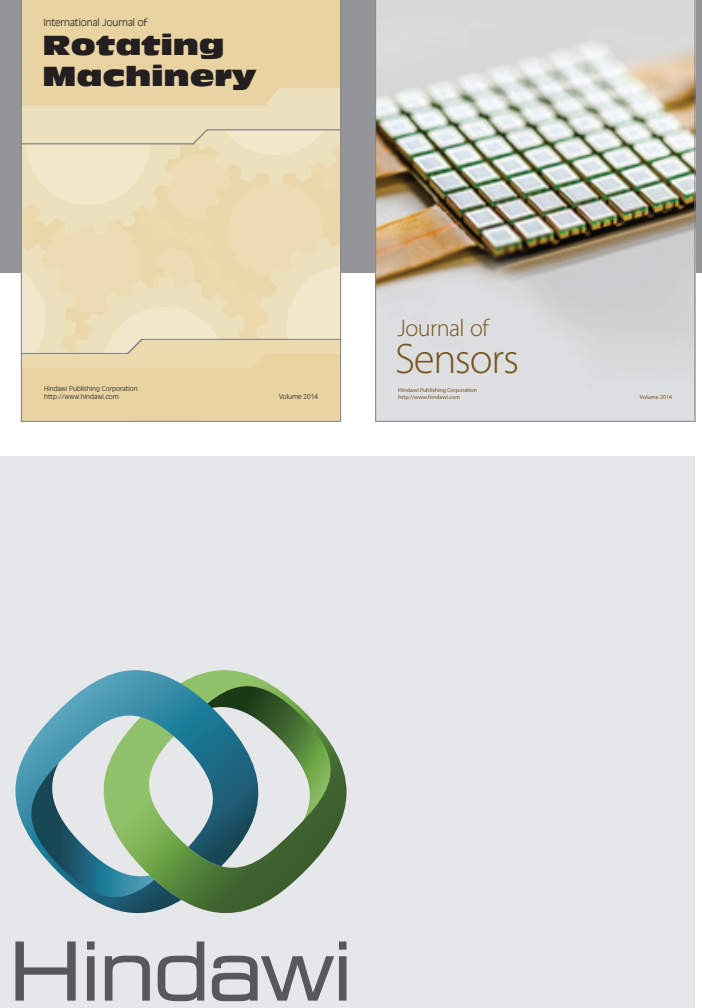

Submit your manuscripts at http://www.hindawi.com
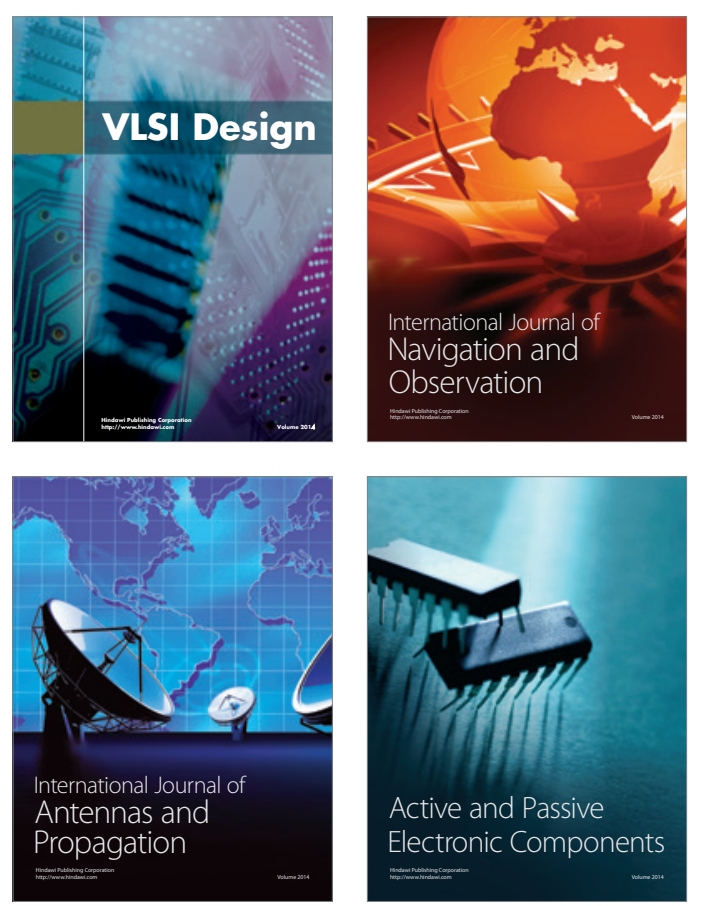
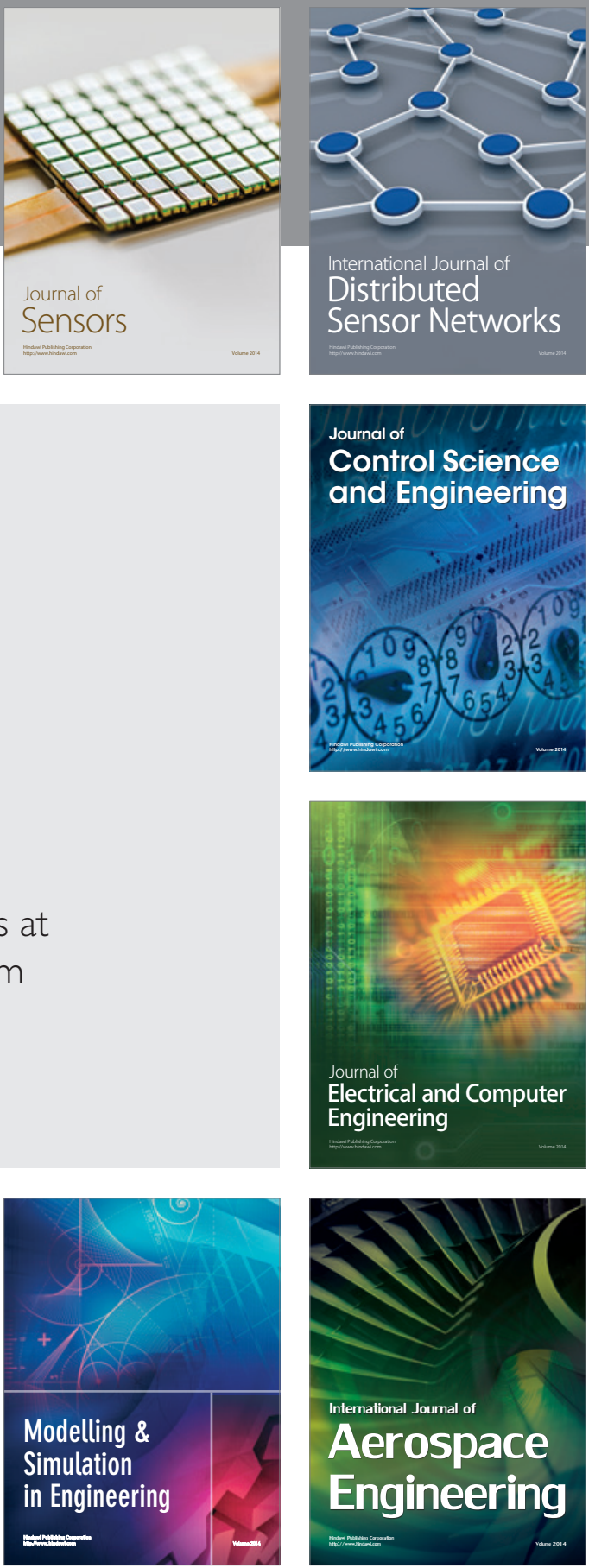

Journal of

Control Science

and Engineering
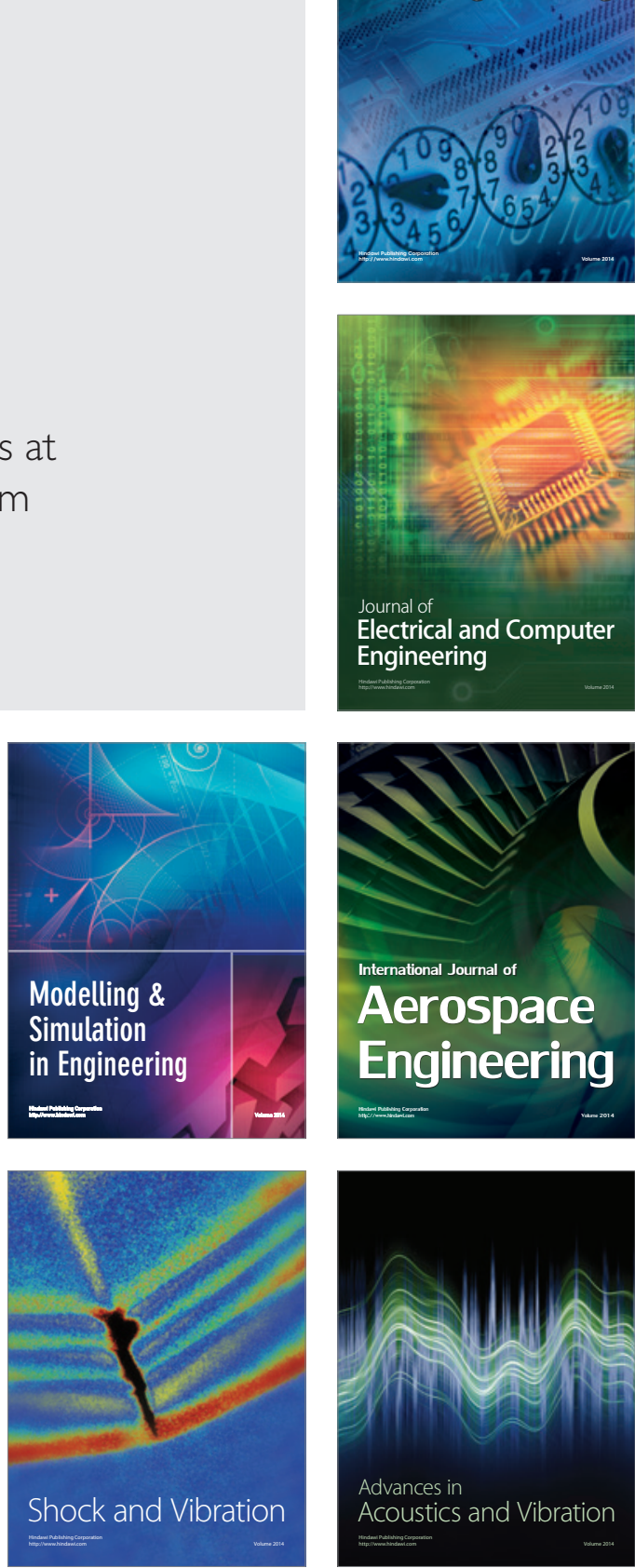